\title{
L'obligation de résultats en éducation, évolutions, perspectives et enjeux internationaux
}

Claude Lessard et Philippe Meirieu, Perspectives en éducation et formation, De Boeck, 2005.

\section{Roger-François Gauthier}

\section{CpenEdition}

\section{Journals}

Édition électronique

URL : https://journals.openedition.org/ries/2013

DOI : 10.4000/ries.2013

ISSN : 2261-4265

Éditeur

France Education international

Édition imprimée

Date de publication : 1 septembre 2006

Pagination : 19-20

ISSN : $1254-4590$

Référence électronique

Roger-François Gauthier, «L'obligation de résultats en éducation, évolutions, perspectives et enjeux internationaux ", Revue internationale d'éducation de Sèvres [En ligne], 42 I septembre 2006, mis en ligne le 07 mars 2012, consulté le 06 juillet 2021. URL : http://journals.openedition.org/ries/2013 ; DOI : https://doi.org/10.4000/ries.2013

Ce document a été généré automatiquement le 6 juillet 2021.

(c) Tous droits réservés 
L'obligation de résultats en éducation, évolutions, perspectives et enjeux internationaux

Claude Lessard et Philippe Meirieu, Perspectives en éducation et formation, De Boeck, 2005.

Roger-François Gauthier

\section{RÉFÉRENCE}

L'obligation de résultats en éducation, évolutions, perspectives et enjeux internationaux, Claude Lessard et Philippe Meirieu, Perspectives en éducation et formation, De Boeck, 2005.

C'est la loi des colloques : tenter de rassembler des intervenants d'origine diverse pour enrichir effectivement une problématique, sans aller toutefois jusqu'à inviter ceux dont on parle! Issu des Entretiens Jacques Cartier tenus à l'Université de Montréal à l'automne 2000, cet ouvrage n'échappe pas à cette remarque impertinente, quelle que soit par ailleurs la qualité du tour de table réuni: la quinzaine d'interventions parviennent à se saisir de la question des résultats en éducation d'une manière particulièrement variée, mais pour autant on a un peu l'impression qui se dégage de ces pièces de théâtre où l'on parle du monstre pendant des scènes entières en évitant de le convoquer. Il rôde entre les pages, il plane au dessus de toutes les argumentations, et il s'appelle en apparence "obligation de résultats", mais sous son vrai nom de «marchandisation de l'école », il ressort de l'affaire en bien mauvais point, étrillé par les propos des participants avec d'excellents arguments. Précisément, la qualité des ces arguments conduit à regretter de n'avoir pu assister au combat décisif sur scène entre les tenants des deux thèses. Faut-il croire que les tenants des «tests " relèvent par exemple tous de l'idéologie, qu'il n'existe pas parmi eux de théoriciens? De chercheurs de bonne foi? 
2 On a compris que ce regret fait partie de l'éloge d'ensemble que mérite cet ouvrage : il traite de ce qui est peut-être la question centrale des systèmes d'éducation en ce début de millénaire, celle des comptes que, selon les uns ou les autres, ces systèmes doivent ou non rendre à la société et il montre en quoi elle est centrale, puisque, aussi bien, en tirant le fil, émergent comme inéluctablement liées à la première la plupart des questions de fond des politiques éducatives.

3 La richesse de l'ensemble vient, outre la valeur propre des interventions, de la richesse même du terrain francophone évoqué face aux questions posées : Belgique francophone (Université de Bruxelles), France (Universités de Paris, Lille 1, Bourgogne et Lyon 2), Québec (Universités de Montréal, Laval et Sherbrooke), Ontario (Universités de Toronto et d'Ottawa), Canton de Genève (Université de Genève) ; la communauté de langue de ces chercheurs permet au lecteur de tirer le meilleur parti de contextes idéologiques et pédagogiques extrêmement divergents, précisément sur la définition des résultats scolaires et sur la lecture qui est faite de ces résultats, de la France qui s'en tient jusqu'ici à un sage système d'examens ${ }^{1}$ à l'Ontario où la place accordée aux tests extérieurs n'a rien à envier à bien des États des États-Unis.

4 Elle naît également de la diversité des postures des chercheurs convoqués : en parallèle à un dialogue sans complaisance qui se poursuit d'article en article sur le fond des choses autour de Claude Lessard, sorte de basse continue, on a le plaisir, sans perdre le fil, de bénéficier des apports de spécialistes de la lecture de l'opinion publique (et on entend avec émotion la parole de Jacky Beillerot), d'un économiste de l'éducation (JeanJacques Paul), d'un spécialiste des politiques éducatives dans les pays en développement (Guy Pelletier, qui nous montre à l'extrême les dégâts que peuvent causer certaines politiques aveuglément tournées vers les "résultats») et d'une psychanalyste clinicienne (Mireille Cifali) : ces apports n'ont rien de décoratif ou de touristique, puisqu'ils nous aident à comprendre l'importance des enjeux de la question, qui, loin d'être une question «à la mode» pour pays post-modernes, concerne la totalité de l'humain.

5 Entre tous les ouvrages qui traitent de ce sujet des "comptes» qui peuvent être demandés à l'école (l'établissement, le maître, l'élève, le système, le pays, etc.), celui-là permet d'avancer, parmi d'autres débats passionnants, pour les trois motifs suivants :

6 - il tient bien le cap entre une critique acerbe, mais précisément documentée, d'une conception des "résultats » en éducation qui correspond à une vision d'intégration libérale aux demandes du marché (auquel les auteurs ne veulent pas remettre les clés de la maison humaine) et une ténacité à rechercher en quel sens et comment, sans perdre son âme, et donc d'une façon conforme à ses valeurs institutrices, l'école pourrait « rendre compte»;

7 - il met bien à jour (voir l'article de Bernard Rey) le fait que le débat sur la seule obligation de résultats est vain si on ne l'ouvre pas à celle de savoir ce que sont ces " compétences" pour ou contre certains seraient prêts à engager des guerres de religion, et au bout du compte si les programmes scolaires sont là pour répondre à une demande sociale, et donc surtout économique, ou s'ils sont institués avec le sens politique le plus haut ;

8 - il établit une relation relativement inédite dans ce type de problématique entre la question des «résultats» et celle de la professionnalité des maîtres. Loin de refuser l'obstacle de l'obligation de résultats individuelle des maîtres, l'ouvrage ouvre des 
pistes, notamment par les plumes de Maurice Tardif et Clermont Gauthier, en tentant de définir limitativement ce que pourrait être la « responsabilité » des maîtres, c'est-àdire en fait de façon ambitieuse, par rapport à la situation traditionnelle, et en référence à ce que Philippe Perrenoud appelle une « obligation de compétences ».

9 Figure du savoir, figure des maîtres et au fond projet pour l'humanité ! Le prix de cet ouvrage est de traiter de l'«obligation de résultats en éducation» avec la focale nécessaire à saisir ces enjeux. Peut-on écrire : « à méditer d'urgence ! »?

\section{NOTES}

1. L'obligation inscrite dans la loi de 2005 de la maîtrise du « socle commun de connaissances et de compétences " montre que, depuis, certaines frontières entre systèmes ont continué de s'estomper et que les continents risquent de se rejoindre pour le meilleur ou, selon les auteurs, pour le pire dans quelque Pampédie uniformisante. 